\title{
A Discourse of the Alienated Youth in the American Culture: Holden Caulfield in J. D. Salinger's The Catcher in the Rye
}

\author{
Samira Sasani ${ }^{1} \&$ Parvaneh Javidnejat ${ }^{1}$ \\ ${ }^{1}$ Dept. of Foreign Languages, Shiraz University, Shiraz, Iran \\ Correspondent Author: Samira Sasani, Dept. of Foreign Languages, Faculty of Literature and Humanities, Shiraz \\ University, Eram Sq., Shiraz, Iran. Tel: 98-713-613-4522. E-mail: samira.sasani21@yahoo.com
}

\author{
Received: January 24, 2015 Accepted: February 23, 2015 Online Published: May 15, 2015 \\ doi:10.5539/ass.v11n15p204 URL: http://dx.doi.org/10.5539/ass.v11n15p204
}

\begin{abstract}
The post-war American society has been depicted in numerous literary works of the American authors among which, J. D. Salinger's The Catcher in the Rye is of significance due to its depiction of one of the most dominant discourses of the period and onward, the alienated youth. The Wars inflicted upon the members of the society an intrinsic wound, the indelible sense of alienation in relation with the world around. The vulnerable youth in particular is a population exposed to such a dangerous phenomenon. Employing Kenneth Keniston's theory of alienation presented in his influential book, The Uncommitted: Alienated Youth in American Society (1965), this paper focuses on Salinger's timeless novel, The Catcher in the Rye (1951) to excavate the symptoms of the alienated youth in Holden Caulfield, the protagonist. In so doing, specific elements would be detected in the American youth; namely: the distrust of commitment, pessimistic existentialism, the feeling of contempt for the self and the people around, aesthetic quest, the fragmentation of identity, the refusal of adulthood and socialization, facing different social problems, the fear of death and having experienced traumatic incidents early in life. The results would show the inevitable probability of any single adolescent suffering from alienation. That is to say no matter what cultural background the youth come from, he or she would eventually inflate with the osmosis of realities of the world around and would resort to the destructive bubble of alienation just as Holden did in The Catcher in the Rye.
\end{abstract}

Keywords: post-war America, alienated youth, Holden Caulfield, Kenneth Keniston

\section{Introduction}

Taking into account the 1950s and the post-world-war traumatic effects on the American society, J. D. Salinger's The Catcher in the Rye could be of significance due to its circulating one of the most dominant discourses of the period in which it was written that is the discourse of the alienated youth. From 1929 to 1939, the latter being the beginning of the Second World War, America had been going through the Great Depression. The war was an antidote to this social state and as Graham (2007) puts it this way, "It left the post-war America in an atmosphere of self-doubt and fear which all lead to a materialistic, consumerist life-style in specially the middle-class" (11).

Apart from Salinger, numerous authors such as Bellow, Heller, and Lee were highly influenced by the aftermath of the war. This paper is inspired by Salinger's famous work and one of the most controversial novels of the post-war era, The Catcher in the Rye, which was composed in 1951. As long as the excavation of the symptoms in the alienated youth is concerned in the novel's protagonist, the paper's main source of backdrop theory would be that of Kenneth Keniston's presented in 1965 book, The Uncommitted: Alienated Youth in American Society.

In so doing, specific features in detecting the alienated youth will be treated; namely: the distrust of commitment, pessimistic existentialism, the feeling of contempt for the self and the people around, aesthetic quest, the fragmentation of identity, the refusal of adulthood and socialization, facing different social problems, the fear of death and having experienced traumatic incidents early in life.

The significance of the study is not in the well-known fact of the protagonist, Holden Caulfield, being considered as an alienated boy, but the application of Keniston's theories in particular to portray the hidden elements of alienation in the character for the first time and finally reaching the conclusion that such socio-psychological issues can as well be detected in a more universal scale rather than merely in the American society and in the ones who have the eyes to see the phoniness of the world around. Adding to the importance of the issue, Chen (2009) in his article probing the adolescent problems in the Catcher in the Rye concludes that: 
Holden represents a social type of adolescents growing up in a corrupt and decadent world and serves a mirror for his peers. There is a lot in him with which the young can identify. Much of Holden's candid outlook on life, on people around him, on society is still relevant to the youth of today and contains a truth of an eternal nature. (p. 146)

It had occurred to Menand and subsequently posted in the American magazine of literary criticism, The New Yorker, that far from the fact of calling Salinger a war writer, what really made Salinger Salinger was inevitably the experience of the war. This claim of Menand has been given credit by citing Salinger's biographers, Ian Hamilton and Paul Alexander in this regard. Menand (2001) defines the war as, "the experience that darkened his [Salinger's] satire and put the sadness into his humor" (p. 4).

Carving out another place for the momentousness of the war in shaping Salinger's literary identity, Miller (1968) opines that:

If we are allowed to read any autobiography at all in his work, we may readily guess that the war was responsible for, or at least brought to the surface, an alienation from modern existence so profound as to manifest itself at times in an overpowering spiritual nausea. (p. 6)

Such notion is manifest in his The Catcher in the Rye and controversies that have long existed surrounding its publication is the main proof of its cultural impact on the youth shaping their mentalities towards life in general.

This is what Graham (2007) describes at the novel's glorious days of public reception:

Catcher was reviewed in newspapers and magazines across the U.S.A. and was generally well received. It was selected as the Book-of-the-Month Club's choice for summer 1951, a situation that guaranteed publicity and sales. . . . Although it was not the best-selling novel of 1951, it stayed on the New York Times best-seller list for the rest of the year. (pp. 7-8)

Along with the bright side of the story promoting the novel's success as an important cultural statement and phenomenon which had been appraised by the members of the American society, due to its use of slang and profanity and for containing adolescent sexuality, the novel was considered by its critics a taboo and was placed in the censorship list of the books that were to be covered in some of the schools in America. Of the many negative reactions towards the novel, here are some examples:

In 1961, the Gablers prepared a "Trash" list including twenty-five books which in their opinion portrayed the conflicts between children and their parents and people in authority, contained questionable language, described sexual acts, and of course to their ultimate disappointment did not depict the family institution as the foundation of the American Life and instead encouraged the indoctrination of American youth with the religion of Humanism training the young subjects to be anti-God, anti-moral, anti-family, anti-free enterprise, and finally anti-American (Jenkinson, 1985, pp. 28-29).

Heightening this image of notoriety, nearly thirty years after its publication, Mark Chapman who murdered John Lennon in 1980 read aloud from the novel at his trial. A copy of Catcher was also found in Hinckley's apartment who had attempted to assassinate President Ronald Reagan in 1981. Such associations intensified the controversies revolving around the novel and provided the critics with more excuses to amplify the boycotting processes. Even a decade after this incident, Anne Levinson, the assistant director of the Office of Intellectual Freedom in Chicago in 1989 condemned the novel. She was quoted in Whitfield's (1997) article, assuming that the novel had been "a perennial No. 1 on the censorship hit list (p. 574)".

All in all, taking the 1950s as a period of ambivalence and difficulty to define, Graham (2007) quoting Medovi comments: "if it were really the oppressive era it is often understood to be, no one would dare to praise a character in a best-selling novel who is both young and non-conformist" (p. 65). Accordingly, with regard to the reception of the work, one can assume that the positive effects which were left behind outweighed the negative ones; so Whitfield (1997) quoting Salzman declares: "no American writer over the past half-century has entranced serious young readers more than Salinger, whose novel about the flight from Pencey Prep may lag behind only Of Mice and Men on public-school required reading lists" (p. 568). Both the attacking and defending statements intensify the extent to which even adults can empathize with such an alienated, non-conformist character as Holden.

\section{Theoretical Framework}

Alienation and non-conformity must have been fashionable terms to have been used in the mid-fifty American society especially among the youth. Holden Caulfield serves as a proper cultural hero who has embraced these two sates through the portrayal of loss and a phony world. He is the emblem of a teenager getting out of the 
control of the family and gradually facing the adversaries of the world outside. Through his quest one cannot help but observe the nonconformist way of his encountering the people around and ultimately taking a deep plunge into an abyss called "alienation". Whitfield (1997) quoting Steinle suggests:

The powerlessness of American adults- as parents, professionals and community leaders- to provide a genuine sense of the future for the adolescents in their charge . . . the novel indicts adult apathy and complicity in the construction of a social reality in which the American character cannot develop in any meaningful sense beyond adolescence. What's more, there is no remedy for this condition as the story is recalled by Holden from a sanitarium in California. (p. 593)

Within such an American culture standing as a microcosm of the world with its entire adolescents facing the similar crisis, very much like Holden, and searching for the Truth, this research tries to excavate the elements of alienation via juxtaposing the pieces of evidence as how Holden symbolizes the American youth carrying the emotional burden of adolescence and how on the way to re-construct reality and conceptions of decency, the youth get alienated from the people around and consequently from the world. Therefore, it is of remarkable relevance to name such a socio-psychological state, "alienation" and detect it in Holden Caulfield.

According to the Meriam Webster's definition of "alienation", when a figure is alienated, there occurs "a withdrawing or separation of that person or person's affections from an object or position of former attachment" (p.28). For Holden, the object is first of all his family and then the world he physically occupies. Harper (1967) suggests that the psychopathic forces get deeper and deeper in the alienated man in America that is doomed to be threatened or gotten desperate by a post-war chaotic universe (p.44). Similarly Whitfield (1997) informs us that:

Holden seems to have sat for psychologist Kenneth Keniston's portrait of uncommitted youth: those who have the most to live for but find no one to look up to; those who are the most economically and socially advantaged but feel the deepest pangs of alienation. (p. 586)

Keniston (1965) in his book The Uncommitted provides us with a clear definition of what is called "unprogramatic alienation" in relationship with American society as a whole:

Historically, most of the alienated have concurrently served some positive goals in whose name they are estranged, be it the radical reconstruction of society, the restoration of ancient verities, the salvation of the soul, national sovereignty, abundance, or opportunity. But these young men find it hard to articulate any clear programs or objectives; and when they do, their values turn out to be private, "aesthetic" and often explicitly irrelevant to the vast majority of men. (p. 75)

As Keniston (1965) implies, not only do the alienated accept self-contempt but they also feel the same towards other people and their frustration with the society comes into a boiling point and the only remained solution would be to draw solid lines and borders between the people around and themselves.

What they want to reach is to pinpoint their own isolation. For them, alienation is an expression of feelings and experiences which cannot be comprehended within the traditional lived American culture (p.83). The question which arises is what had been done to an American adolescent so that they deserve being this much pushed away; Keniston (1965) clarifies the issue as such:

Alienation is a response of individuals especially sensitized to reject American culture by their early development, a development which in part reflects their families' efforts to solve dilemmas built into American life; and it is in part a response to social stresses, historical losses, and collective engagements in our shared existence. (p. 391)

In addition to family and society in general, another complicated factor for the alienated to run away from, is the opposite gender and the relationship with them. Sexuality has been believed to blossom on the road of moving towards experience and maturity; thus, the young alienated cannot function and are caught in between the dependency-based years of their childhood and the adult world's demanding for a high degree of self-sufficiency; such paradox in the upbringing of the American children would naturally result in perplexity that is actually Keniston's (1965) "fantasy of fusion":

First he must move from childhood to the youth culture, learning its way and adapting to its requirements; and later, when he "drops out" of the youth culture or is expelled by commencement, he must make a second transition into the "real" world of grownups. (p. 395)

Keniston (1965) believes that in all their wanderings and exploration of the real world, the alienated remain observers not participants (p. 93). 
The anxiety of historical dislocation as another characteristic of the alienated is what Keniston (1965) refers to as, "the feeling of unrelatedness, of being adrift, of not being able to catch hold of anything or anyone in our rapidly shifting society" (p. 240). The alienated accept that their claims regarding the universal truth are subjective and on the route of seeking the truth; they embark on an aesthetic quest that involves living for today but in the past. In this quest lie self-expression, creativity, passion, emotion, feeling, isolated individualism and other factors that stand in complete opposition to the American outlook which has long been portrayed in the definition of the American Dream and the self-made man discourse in the era.

\section{Discussion}

All the aforesaid factors are the ones seen in Holden Caulfield, the alienated man. Commencing with the will to get away from the people around, this is exactly how Holden is dragging on through his life; jumping from one school to another, not feeling at home in any one of them, and finally finding out the fact that he cannot be bothered living among human beings. All he suggested as a clear program which is in reality unclear and "unprogramatic" in words of Keniston (1965), was the fantasy of withdrawal to the countryside copulating with a deaf and dumb wife and holding a job as a catcher in the rye, preventing innocent children from falling into the abyss of growing up and experience. Nevertheless, coming more to his senses and understanding that he is living in a real capitalist society, he ultimately chooses a job but as he says, "I didn't care what kind of job it was, though. Just so people didn't know me and I didn't know anybody" (Salinger, 1951, p. 198).

Naturally, hatred or better to say "contempt" in Keniston's words is the origin of such retreatment from society. For Holden, this feeling is targeted towards self as well; self-contempt is shown in his statements about himself, "I'm a moron" (Salinger, 1951, p. 14); "I'm the most terrific liar you ever saw in your life, it's awful" (Salinger, 1951, p. 16); "I swear to God I'm a madman" (Salinger, 1951, p. 134). The contempt he feels towards others is more explicitly conveyed. Nardi (2009) quoting Edwards affirms:

Holden is under the impression that he alone possesses a supreme degree of insight and intelligence knowing what is best for the world and himself. Holden is unwilling to take any advances toward self-improvement, which is itself an indication of immaturity. (p. 37)

Solely using the term "people" would create a chasm separating the speaker from those around and this is where Holden's judgmental statements about others walk in, "sometimes I act a lot older than I am. I really do- but people never notice it. People never notice anything" (Salinger, 1951, p. 9); "I call people 'prince' quite often when I'm horsing around. It keeps me from getting bored or something" (Salinger, 1951, p. 24); "people never believe you" (Salinger, 1951, p. 37); "people are always ruining things for you" (Salinger, 1951,p. 87); "I hated people once in a while" (Salinger, 1951, p. 187); and "I didn't care what kind of job it was, though. Just so people didn't know me and I didn't know anybody" (Salinger, 1951, p. 198).

Holden continuously feels nausea and claims to be on the verge of puking because of a suffocating world which denies innocence. "It kills" is repeatedly mentioned in the novel; he hates the phony world: "Grand. There's a word I really hate. It's a phony. I could puke every time I hear it" (Salinger, 1951, p. 9). This nausea is demonstrative of the alienated attitude from the side of "normal" community.

"Rejection of culture" as another sustaining element Keniston draws upon, exists in Holden's belief. He is mature enough to observe the social stresses which are discernible in the society; he is bent on criticizing the consumerist life-style; to illustrate, the situation in which the school principal would spend much time talking with the rich parents about their children's progresses and would ignore those of the lower social class. The refutation lies in the repudiation of the people living within his culture. Holden constantly refers to the Americans around as "phony": "One of the reasons I left Elkton Hills was because I was surrounded by phonies" (Salinger, 1951, p. 13). "Pencey was full of crooks" (Salinger, 1951, p. 4). Keniston (1965) believes that in the world view of adolescents, "Men are either weak and phony or (less likely) monsters; that women are either possessive and controlling or immensely comforting and nurturing; that all interpersonal situations are quintessentially rivalrous triangles" (p. 156). Even so, it is necessary to mention the paradox which lies in Holden's ways. He is never-endingly shunning the people around and at the same time goes out of his way to communicate with them and find someone to talk with. Saleem (2014) in this regard cites: "alienation is cogent to existence as an inherent solipsism enshrouds the subconscious even while the mind is consciously attempting to reach out to other living beings to make life meaningful" (p. 69).

As an attempt to fight the evils of the society, however in vein, Holden on a visit to the Museum of Natural History awaiting his little sister Phoebe, tries to rub off the "Fuck yous" from the walls. This place has always been Holden's favorite place where he would feel stability and the state of nothing-is-going-to-change. But, revisiting the place, he sees those swear words on the walls and swears to God that there would be no single 
place in the whole world not being marked by these words that is another proof for the disillusionment of his prophetic mission and vision as a catcher in the rye. The society around him is rapidly changing and he cannot keep up with the pace.

Holden asserts a sort of non-conformity through keeping a mentality in total opposition with others and at the same time by conspicuous acts such as wearing a red hunting hat in public and being a "chimney" as he himself relates to his habit of smoking. He is in his own way rejecting the society by breaking the laws whereas he seems to be quite unaware of the fact that he is the oxymoron contradicting what he thinks with what he does; for instance, he criticizes the Hollywood filmmaking industry and at the same time goes watching them and keeps hating people but at the end of the novel, he admits his being in a phase and tells the reader that he misses those people he once considered phonies. All these conflicts reflect the uprootedness and the sense of belonging nowhere.

Regarding sexual behavior, for Holden such matters seem to be quite sophisticated and funny at the same time. "I like to be somewhere at least where you can see a few girls around once in a while, even if they're only scratching their arms or blowing their noses or even just giggling or something" (Salinger, 1951, p. 3). Jane Gallagher, an old friend of him, could not really be put off Holden's mind as he himself says. "I kept thinking about Jane, and about Stradlater having a date with her and all. It made me so nervous I nearly went crazy. I already told you what a bastard Stradlater was" (Salinger, 1951, p. 32). Accordingly, we can presume that the alienated are not different from the other groups regarding the emotions exercised, namely jealousy.

In addition to Jane as a seemingly long-lasting love, there exist other female characters showing up in the novel towards whom Holden expresses strange emotional circumstances; for example, Sally Haze who was an old girlfriend. He tells us, "I wasn't too crazy about her" (Salinger, 1951, p. 105). Despite this, when he sees her again after a while he confesses, "I felt like marrying her the minute I saw her" (Salinger, 1951, p. 124). His statement is quite weird and seems funny though not to himself. On his excursions in the night clubs he meets a dancing girl named Bernice who makes him say, "I was halfly in love with her by the time we sat down" (Salinger, 1951, p. 73). He flirts with women older than him but when the time comes to get serious and take action, he holds back; for instance, the moment he hires a prostitute in the hotel and is determined to lose his virginity, "Women kill me. They really do. I don't mean I'm oversexed or anything like that- although I am quite sexy. I just like them, I mean" (Salinger, 1951, p. 54). All in all, the attitude he has regarding sex is dubious:

In my mind, I'm probably the biggest sex maniac you ever saw. . I keep making up sex rules for myself, and then I break them right away. . . sex is something I just don't understand. I swear to God I don't. (pp. $62-63)$

Holding a pessimistic ideology, Holden can be considered a person practicing an existentialist viewpoint about future carrying with him anxiety in a universe that is supposed to be chaotic, unconstructed and meaningless wherein the impossibility of true communication exists. Unable to be the kind of man required by prep schools and corporations, Salinger's protagonist could find no exit within the American society (Whitfield, 1997, p. 584). The "distrust of commitment" which Keniston elaborates on, is also a consequence of such pessimism. Holden distrusts commitment not only in interpersonal interactions but also in the form of shouldering responsibilities and rejecting group activities. He is influenced in his academic progresses and discussing beyond that, his extracurricular activities are also affected by his state of being alienated. Being responsible for a college organization, that is to say being the manager of the fencing team, he only remains in position for a short time and once again could not hold it as one would expect of a person with such a name. He leaves all the equipment in the subway station and becomes the target of his fellow sports group mates' reprimand and the point is that he could not care less.

The fear of ageing and physical decline which is ultimately death and also obsession with loss and leaving are always with Holden. The whole image disgusts him; for example, he expresses his inner thoughts to us in his farewell-before-dropping out-visit to his old history teacher: "You take somebody old as hell, like old Spenser, and they can get a big bang out of buying a blanket" (Salinger, 1951, p. 7). It is needed to mention though that his assumption that everything is worthless is just the normal feeling people have when someone they love dies.

Life starts to seem a pathetically transparent attempt to trick them into forgetting about death; they lose their taste for it (Menand, 2001, p. 4). Being quite concerned about dying he mentions: "you felt like you were disappearing every time you crossed a road" (Salinger, 1951, p. 5); "I felt so lonesome, all of a sudden, I almost wished I was dead" (Salinger, 1951, p. 48). Leaving and loss are reflected in his incessant questioning of the whereabouts of the ducks at the Central Park Lagoon as he demands the answer from every cab driver in whose 
car he sits. This inquisition symbolically points out the premonition he has for each loss in life and the response which is not there that is the existential absurdity.

Highlighting the fear of death and aging, the dilemma is that Holden is neither adult nor child; this being stuck in between the continuum makes him confused and results in his incapacity to act adequately where and when needed. This vacillation is manifested in Harper's (1967) statement:

[Holden] is conscious of being trapped in the no-man's-land between two worlds, between his beautiful but impossible ideals and a sordid but inescapable reality. . . his acceptance of society (in the end) is an acceptance of the fact that he will always be deeply estranged from its dominant social values and, in a sense, a stranger to its people as well. (pp. 69-70)

Another feature of alienation is reluctance towards agency; that is to say, being an observer rather than the active subject. In this regard, in the beginning of the novel all the students are watching the football game with Saxton Hall in the stadium actively and vehemently supporting their team, but Holden is standing on a hill observing the game from high above; that is the place he comes up with the idea of leaving Pencey Prep sooner than the due time. Even in his stay in the hotel in New York, he is observing the erotic sexual plays of the other people in the buildings around but when it comes to his own time with the prostitute, he simply rejects getting involved in the real action.

The Observer in the Rye would be a substitute title for the novel suggested to Salinger; he could have used it on the front cover with the picture of a carousel going round and round with Phobe, Holden's little sister, on one of the horses and similarly as the end of the novel portrays, Holden sitting under the rain observing the innocent trying to hold out hands for the golden ring of experience above the horses despite the fact that they could simply fall. Holden confesses after all that children need to be allowed reaching for it. Being the Catcher turned out to be an illusion for him.

As for the origin of all this alienated behavior, the issue of family and the probable traumas early in life can be discussed. Holden has had a rather loose upbringing from the part of his family. What can one expect of a traumatized mother and father who had already lost a son because of leukemia? Definitely being barely conscious of it, they transferred the grief to their other son. This contagious sorrow is visited upon Holden and subsequently makes other aspects of his life bitter and traumatic as well. The absence of sufficient parental care is the result and as Wannamaker (2008) quoting Kindlon and Thompson states, "Boys suffer deeply as a result of the destructive emotional training our culture imposes upon them, that many of them are in crisis, and that all of them need help" (p. 1). The father image of whom we expect to provide such support is the one Holden describes as "Nice... but touchy as hell" (Salinger, 1951, p. 1). Rather than being someone on whom he can rely, Mr.Caulfield is a distant and uninvolved father in name only. As a result of such a cold relationship, there would be no rebelling against such fathers and on the other hand the American teenagers, in general, can simply not be bothered trying to amend the loose bond between them and their parents.

Holden as one of the loneliest characters in fiction can also be distinguished as a traumatized teenager. Graham (2007) opines that the origin of "trauma theory" goes back to Freud's formulation of the impact on a person of a repressed or unspeakable experience which is that much painful as to be buried in the unconscious and ultimately shapes the individual's responses to subsequent experiences without being recognized or healed (p. 103). The novel telescopes the eternal piercing mark on Holden which are the results of the experiences of his brother's death with whom he used to feel great affinity and the death of a schoolmate, James, who commits suicide by jumping out the window as a defensive mechanism in front of the school bullies. Holden permanently mourns over his deceased sibling by keeping his memory ultra-fresh: "What I did, I started talking, sort of loud, to Allie. I do that sometimes when I get very depressed" (Salinger, 1951, p. 98). As Graham (2007) declares, "In the grip of this grief, Holden becomes ever more grimly convinced of his own imminent death" (p. 104).

Aesthetically looking at the whole issue of alienation, Holden childishly ignores what future would hold for him and at the same time tries to live in the innocent world of childhood or at its best condition, keeps it untouched and intact for children like his little sister. The truth for him is not when "a body catch a body coming through the rye" (Salinger, 1951, p. 93), but "If a body meet a body coming through the rye" (Salinger, 1951, p. 93), as little Phobe corrected the line of the song misheard by her brother. This is what Keniston coins as the "aesthetic quest" in which an alienated youth might get involved.

\section{Conclusion}

For the uncommitted Holden this alienation culminates in the distortion of his soul, bitterness, nausea, and the ultimate obsession causing withdrawal into death. According to Miller (1968): 
The causes of the alienation are frequently obscure but always complex. Sometimes society seems at fault, in the horrors of racial prejudice or the horrors of war. But sometimes the fault seems to lie in a failure of personal relationships. . . Sometimes, however, the cause of alienation lies deeply within, in a turbulence of the spirit, plunging the individual into a dark night of the soul, or dazzling him in the ecstasy of a vision of mystical union, two radically different states that mystics have always found in close conjunction. (p. 20)

Holden Caulfield's transformation from a fictional character into a cultural hero helped to confirm the belief that Holden's unhappiness is less personal than it appears; that it is really some sort of protest against modern life. It also helps to confirm the sense encouraged by Salinger's own later manner [the author's retreating from society], that there is no distinction between Salinger and his characters (Menand, 2001, pp. 6-7). Salinger depicts a dominant discourse of alienation which has been made by history and prescribes it to a society via creating the character of Holden, an adolescent who symbolizes the isolated, difficult-to-fit American teenage still bearing resemblance to all the teenagers worldwide even sixty and so years, after writing the novel; no matter how much it has been proscribed.

This is a strong evidence to prove that the world has not changed at all. No matter how many atomic bombs with Holden sitting on top are launched; there remain wounds throughout history that cannot be healed. Such is the alienation created deep inside the adolescents of a society which continues to spread through the infected subject. Salinger's dubious ending of the novel might evoke the possibility of the wound being cured in a caring center from which Holden recalls the plot of the story. Alongside the symptoms of an alienated figure which were highlighted through using Keniston's theory, literature helps shape the culture in which it originates from and sometimes can trespass the geographical boundaries. Alienation has always existed as a term, but The Catcher in the Rye has assisted its readers to realize the existence of the notion deep down in possibly every single one of us.

\section{References}

Chen, L. (2009). An Analysis of the Adolescent Problems in The Catcher in the Rye. Asian Social Science, 5(5), 143-146. http://dx.doi.org/10.5539/ass.v5n5p143

Graham, S. J. D. (2007). Salinger's The Catcher in the Rye. New York: Routledge.

Harper, M. H. (1967). Desperate Faith: a study of Bellow, Salinger, Mailer, Baldwin, and Updike. Chapel Hill: North Carolina Press.

Jenkinson, E. B. (1985). Protecting Holden Caulfield and His Friends from the Censors. The English Journal, 74(1), 26-33. http://dx.doi.org/10.2307/816502

Keniston, K. (1965). The Uncommitted: Alienated Youth in American Society. New York: Harcourt, Brace \& World.

Menand, L. (2001, September 27). Holden at Fifty: The Catcher in the Rye and what it spawned. The New Yorker: Fact. Retrieved May 20, 2014, from http://www.newyorker.com/magazine/2001/10/01/holden-atfifty

Miller, J. E. J. D. (1968). Salinger. Saint Paul: The North Central Publishing Company.

Nardi, S. (2009, Fall). The Internal Conflicts of Holden Caufield. E-Scriptor, 32-49.

Saleem, A. (2014). Theme Of Alienation In Modern Literature. European Journal of English Language and Literature Studies, 2(3), 67-76.

Salinger, J. D. (1951). The Catcher in the Rye. Boston: Little, Brown and Company.

Wannamaker, A. (2008). Boys in Children's Literature and Popular Culture. New York: Routledge.

Whitfield, S. J. (1997). Cherished and Cursed: Toward a Social History of The Catcher in the Rye. The New England Quarterly, 70(4), 567-600. http://dx.doi.org/10.2307/366646

\section{Copyrights}

Copyright for this article is retained by the author(s), with first publication rights granted to the journal.

This is an open-access article distributed under the terms and conditions of the Creative Commons Attribution license (http://creativecommons.org/licenses/by/3.0/). 